\title{
DESEMPENHO AGRONÔMICO DE CULTIVARES DE MARACUJÁ (PASSIFLORA EDULIS SIMS F. FLAVICARPA) NAS CONDIÇÕES AMBIENTAIS DE COLORADO DO OESTE, RONDÔNIA
}

Sávio Ribeiro Rosa1, Damaris Suelen Nascimento², Maria Fernanda Monteiro da Silva $^{3}$, Hueber da Cruz Damasceno ${ }^{4}$

${ }^{1}$ Acadêmico do Curso de Engenharia Agronômica do Instituto Federal de Rondônia Campus Colorado do Oeste (IFRO), Colorado do Oeste-RO, Brasil.

2Professora Mestre do Ensino Básico, Técnico e Tecnológico do Instituto Federal de

Rondônia Campus Colorado do Oeste (IFRO), Colorado do Oeste-RO, Brasil.

E-mail: damaris.nascimento@ifro.edu.br

${ }^{3}$ Acadêmica do Curso de Engenharia Agronômica do Instituto Federal de Rondônia Campus Colorado do Oeste (IFRO), Colorado do Oeste-RO, Brasil.

${ }^{4}$ Estudante do Curso Técnico em Agropecuária do Instituto Federal de Rondônia Campus Colorado do Oeste (IFRO), Colorado do Oeste-RO, Brasil.

Recebido em: 15/05/2020 - Aprovado em: 15/06/2020 - Publicado em: 30/06/2020 DOI: 10.18677/EnciBio_2020B22

\begin{abstract}
RESUMO
O trabalho ocorreu durante o período de 2018/2 - 2019/1, no município de Colorado do Oeste - Rondônia, com objetivo de avaliar a produção de cultivares de maracujá ( $P$. edulis f. flavicarpa). Foram utilizados 10 cultivares de maracujá, em delineamento inteiramente casualizado, com cinco repetições e seis plantas por parcela. Assim, ao todo, foram quarenta unidades experimentais e 300 plantas. Para produção no período chuvoso, a FB-200, BRS RUBI e UNEMAT 530 tiveram melhor resultado. Em relação a produção no período de seca as cultivares que sobressaíram foram a UNEMAT 510 e BRS RUBI. O resultado indica que a cultivar que possibilita maior produção na região, gerando uma possibilidade de geração de renda é a BRS RUBI.

PALAVRAS-CHAVE: maracujazeiro, fruticultura, variedades.
\end{abstract}

\section{AGRONOMIC PERFORMANCE OF PASSION FRUIT CULTIVARS (PASSIFLORA EDULIS SIMS F. FLAVICARPA) IN THE ENVIRONMENTAL CONDITIONS OF WEST COLORADO, RONDÔNIA}

\begin{abstract}
The work took place during the period of $2018 / 2$ - 2019/1, in the municipality of Colorado do Oeste, in the state of Rondônia, with the objective of evaluating the production of passion fruit cultivars ( $P$. edulis f. flavicarpa). Ten passion fruit cultivars were used, in a completely randomized design, with five replications and six plants per plot. Thus, in all, there were forty experimental units and 300 plants. For water production, the FB-200, BRS RUBI and UNEMAT 530 had the best result. Regarding dry production, the cultivars that stood out were UNEMAT 510 and BRS RUBI. The work indicates that the cultivar that allows greater production in the region, generating a possibility of generating income is BRS RUBI.
\end{abstract}

KEYWORDS: passion fruit, fruit growing, varieties 


\section{INTRODUÇÃO}

O maracujá é pertencente à família Plassiforaceae, sendo distribuída em regiões temperadas, composta por 18 gêneros e mais de 630 espécies. Desde 1995, a área plantada com maracujá-azedo, no Brasil, vinha se mantendo ao redor de 36 mil hectares, mas em 2007, houve um aumento expressivo de $30 \%$ da área plantada que foi de 46.866 ha. Em 2010, a área plantada foi de 62.200 ha com uma produção 920.000 t (FALEIRO, 2012). Os principais países produtores mundiais de maracujá são: Brasil, Colômbia, Equador e Peru (SANTOS, 2016).

O maracujá-azedo (Passiflora Edulis Sims) é um fruto com potencial em climas tropicais e subtropicais (LAGES, 2015). Sendo a espécie mais cultivada no Brasil por ser mais vigorosa e apresentar frutos de maior tamanho. Em 95\% dos pomares comerciais do país encontra-se o maracujá azedo, com uma produção anual, em 2009, em torno de 731.515 toneladas representando cerca de $\mathrm{R} \$ 669$ milhões. Passiflora Alata Curtis, é a segunda espécie mais cultivada, conhecida como maracujá doce que vem ganhando importância dentro do mercado de frutas in natura devido aos preços diferenciados e sua baixa acidez (MOURA, 2013). O maracujá-roxo é destinado na sua maioria para o mercado de frutas frescas, por ser mais doce e menos ácido que a espécie amarela (CEPLAC, 2015).

A produção e comercialização do maracujá exerce importante papel econômico e social à agricultura familiar, possibilitando geração de renda em pequenas propriedades, além de colaborar para permanência do homem no campo (FALEIRO; JUNQUEIRA, 2016). Sendo o Brasil o maior consumidor e produtor mundial de maracujá. Segundo dados da EMBRAPA (2016), o País se destaca com uma produção de aproximadamente 1 milhão de toneladas/ano. Porém, essa produtividade ainda é considerada baixa, tendo dois fatores principais que podem influenciar essa questão: a não realização do manejo adequado (podas de formação, polinização manual, irrigação e controle fitossanitário, entre outros) e a não utilização de cultivares modificadas geneticamente, pelo fato de ainda haver muitos produtores que utilizam sementes sem origem genética.

O número de cultivares comerciais é considerado pequeno, considerando a grande variabilidade dos agroecossistemas no Brasil. Muitas vezes não se utiliza sementes de variedades melhoradas, aproveitando-se somente sementes de plantios anteriores, as quais normalmente apresentam baixo desempenho agronômico. Além de não se ter utilização de cultivares melhoradas, a baixa produtividade média do maracujá ocorre devido a problemas fitossanitários e técnicas inadequadas de cultivo (CUNHA, 2013).

Esperando com a pesquisa produzir informações relevantes sobre a tecnologia de produção de maracujá, assim como, apontar as diferenças agronômicas entre as cultivares avaliadas, possibilitando recomendações aos agricultores da região, sobretudos à agricultores familiares, que veem na fruticultura uma possibilidade de geração de renda. Objetivou-se avaliar a produtividade de 10 cultivares de maracujá sob as condições edafoclimáticas de Colorado do Oeste Rondônia.

\section{MATERIAIS E MÉTODOS}

O projeto foi implantado na Chácara Nossa Senhora Aparecida, localizada à Avenida Amazonas, 6003, zona rural do município de Colorado do Oeste, Estado de Rondônia. O delineamento utilizado foi em delineamento inteiramente casualizado, com cinco repetições e seis plantas por parcela. Os tratamentos são constituídos de 10 cultivares de maracujá, sendo eles FB-200 T1, FB-300 T2, FELTRIN T3, IAC 277 T4, UNEMAT 510 T5, BRS GIGANTE AMARELO T6, BRS RUBI T7, UNEMAT 530 
T8, SCS437 T9 e SC T10. Assim, ao todo, foram quarenta unidades experimentais (5 repetições $X 10$ tratamentos) e 300 plantas.

FIGURA 1 - Croqui da área

Cerca/Estrada

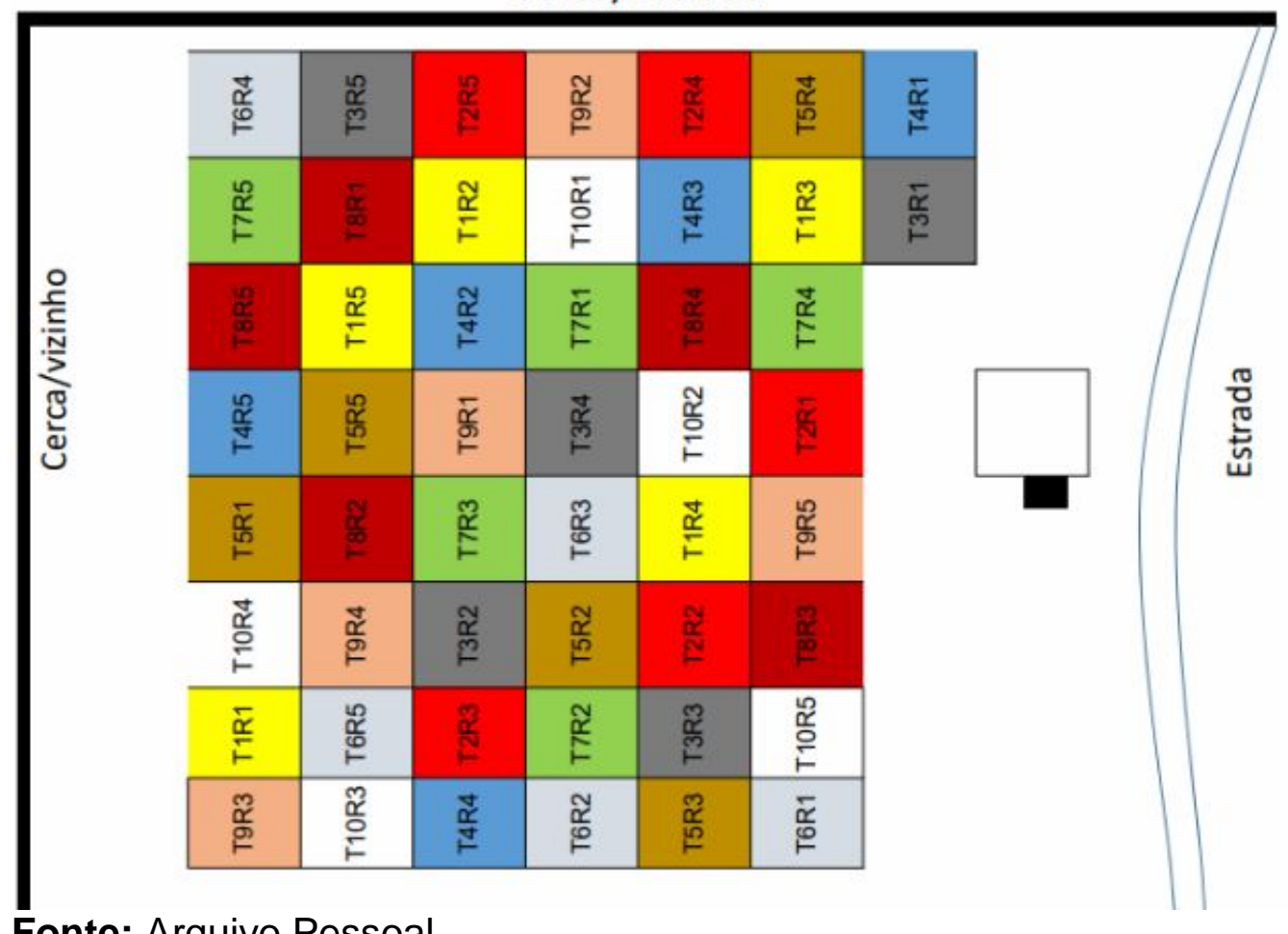

Fonte: Arquivo Pessoal

As mudas utilizadas foram obtidas no viveiro do IFRO Campus Colorado. No mês de agosto de 2017, quando as mudas atingiram a altura aproximada de $30 \mathrm{~cm}$, foi realizado o transplantio em covas, no espaçamento de 2,0 m por 3,0 m. Entre uma unidade experimental e outra foi deixado um espaço de $1 \mathrm{~m}$. A adubação foi feita de acordo com o livro Manual do Cerrado (BRAGA et al., 2004). Utilizando ureia como fonte de nitrogênio, superfosfato simples como fonte de fósforo e cloreto de potássio como fonte de potássio. Sendo que a ureia e cloreto de potássio foram aplicados mensalmente (outubro de 2018 a setembro de 2019) nas seguintes quantidades: $18,51 \mathrm{~g}$ de ureia e $34,70 \mathrm{~g}$ de cloreto de potássio por planta. Já o superfosfato simples foi aplicado uma única vez, na dose de $500 \mathrm{~g}$ por planta, logo no início da avaliação em outubro de 2018.

O sistema de condução e sustentação das plantas ocorreu em espaldeira vertical, com as estacas de sustentação a uma distância de $8,0 \mathrm{~m}$ e um fio de arame liso a 2,0 m de altura em relação ao solo. As plantas foram conduzidas em haste única até o fio de arame, e os ramos secundários (dois), orientados para os dois sentidos da espadeira. Quando as plantas atingiram a altura de $20 \mathrm{~cm}$ acima do arame foi efetuada a poda apical da haste principal e os ramos secundários atingiram $1,5 \mathrm{~m}$ de crescimento, no sentido horizontal da espaldeira, também foi efetuada a poda apical desses ramos.

O controle de plantas daninhas foi realizado por meio de roçada entre linhas e capina manual entre plantas e controle de doenças e/ou insetos quando necessário. Durante o período reprodutivo foi feita a polinização manual da lavoura e no período da seca as plantas foram irrigadas por gotejamento de acordo com a necessidade da cultura. 
Após maturação, os frutos foram colhidos do chão, à medida que foram caindo, diariamente e devidamente separados, de acordo com a cultivar, e encaminhados para as avaliações.

As variáveis avaliadas foram: produção por hectare $(\mathrm{kg})$, produção total $(\mathrm{kg})$, produtividade por planta $(\mathrm{kg})$, número de frutos por planta (NFP), número de frutos por hectare (NFH). Tendo também diversas variáveis relacionadas aos frutos (massa fresca do fruto (MF) em gramas (g); massa média do fruto (MMF), em gramas (g), espessura da casca $(\mathrm{cm})$, diâmetro longitudinal e transversal do fruto $(\mathrm{mm})$.

Os dados obtidos foram submetidos a análise de variância (Teste "F") ao nível de $5 \%$ de probabilidade e posteriormente ao teste estatístico de Scott-Knott (5\%) para agrupar as cultivares.

\section{RESULTADOS E DISCUSSÃO}

As cultivares FELTRIN e SCS 437 produziram frutos com maio massa média, sendo respectivamente $311,86 \mathrm{~g}$ e $282,92 \mathrm{~g}$. Em relação a massa média da polpa os cultivares analisados não diferiram estatisticamente. (Tabela 1)

TABELA 1. Massa média do fruto $(\mathrm{g})$ e massa médio da polpa $(\mathrm{g})$ das diferentes cultivares de maracujá, cultivadas no município de Colorado do Oeste - Rondônia.

\section{Cultivares}

Massa média do fruto

(g)
Massa média da polpa

(g)

\begin{tabular}{ccc}
\hline FB-200 & $239,56 \mathrm{~B}$ & $134,58 \mathrm{~A}$ \\
FB-300 & $211,80 \mathrm{~B}$ & $117,61 \mathrm{~A}$ \\
FELTRIN & $311,86 \mathrm{~A}$ & $162,50 \mathrm{~A}$ \\
IAC 277 & $255,96 \mathrm{~B}$ & $119,76 \mathrm{~A}$ \\
UNEMAT 510 & $248,76 \mathrm{~B}$ & $126,56 \mathrm{~A}$ \\
BRS GIGANTE AMARELO & $262,84 \mathrm{~B}$ & $138,40 \mathrm{~A}$ \\
BRS RUBI & $235,56 \mathrm{~B}$ & $131,76 \mathrm{~A}$ \\
UNEMAT 530 & $215,28 \mathrm{~B}$ & $118,56 \mathrm{~A}$ \\
SCS 437 & $282,92 \mathrm{~A}$ & $140,24 \mathrm{~A}$ \\
SC & $247,40 \mathrm{~B}$ & $117,48 \mathrm{~A}$ \\
\hline CV $(\%)$ & 16,15 & 21,97 \\
\hline
\end{tabular}

Médias seguidas de letras diferentes, (maiúscula) na coluna, diferem entre si ao nível de $5 \%$ de probabilidade de erro pelo teste Scott-knott $(p<0,05)$.

Em relação a produção nas águas, a cultivar FB-200 possui alta produtividade de massa média dos frutos e maior resistência na casca enquanto a UNEMAT 530 devido ter sido criada para se adaptar ao clima e solo da região norte, obteve-se alta quantidade de frutos por planta e elevada massa fresca dos frutos, devido essas características obtiveram melhores resultados, apresentando respectivamente os seguintes valores $40.953,84 \mathrm{~kg} \mathrm{ha}^{-1}$ e $47.426,60 \mathrm{~kg} \mathrm{ha}^{-1}$. Seguidas das cultivares FB300, IAC 277, UNEMAT 510 e SCS 437. Já as demais não tiveram um bom desempenho. A cultivar BRS Rubi devido ser uma cultivar melhorada a partir de cultivares silvestres selecionadas pela produtividade alta, alto teor de polpa e maior resistência as pragas, devido apresentar maior espessura de casca, se destacou tanto no período das águas, quanto no da seca, com 43.032,36 $\mathrm{kg} \mathrm{ha}^{-1} \mathrm{e} 43.977,84$ $\mathrm{kg} \mathrm{ha}^{-1}$ respectivamente. Outra que se destacou no período da seca foi a UNEMAT $510\left(39.905,12 \mathrm{~kg} \mathrm{ha}^{-1}\right)$ pelo fato de apresentar características semelhantes a cultivar UNEMAT 530. Porém BRS GIGANTE AMARELO $\left(24.911,76 \mathrm{~kg} \mathrm{ha}^{-1}\right)$ e SCS 
$437(17.168,32 \mathrm{~kg} \mathrm{há-1})$ não apresentaram alta produção em comparação com as demais (Tabela 2).

TABELA 2. Produção nas águas $\left(\mathrm{kg} \mathrm{ha}^{-1}\right)$ e produção na seca $\left(\mathrm{kg} \mathrm{ha}^{-1}\right)$ de diferentes cultivares de maracujá, cultivadas no município de Colorado do Oeste - Rondônia.

\begin{tabular}{ccc}
\hline Cultivares & $\begin{array}{c}\text { Produção nas águas } \\
\left(\mathbf{k g ~ h a} \mathbf{~}^{-1}\right)\end{array}$ & $\begin{array}{c}\text { Produção na seca } \\
(\mathbf{k g ~ h a}\end{array}$ \\
\hline FB-200 & \\
FB-300 & $40953,84 \mathrm{~A}$ & $35186,84 \mathrm{~B}$ \\
FELTRIN & $34424,40 \mathrm{~B}$ & $32918,60 \mathrm{~B}$ \\
IAC 277 & $25347,24 \mathrm{C}$ & $31648,08 \mathrm{~B}$ \\
UNEMAT 510 & $33306,64 \mathrm{~B}$ & $34851,76 \mathrm{~B}$ \\
BRS GIGANTE AMARELO & $35620,48 \mathrm{~B}$ & $39905,12 \mathrm{~A}$ \\
BRS RUBI & $25938,52 \mathrm{C}$ & $24911,76 \mathrm{C}$ \\
UNEMAT 530 & $43032,36 \mathrm{~A}$ & $43977,84 \mathrm{~A}$ \\
SCS 437 & $47426,60 \mathrm{~A}$ & $34100,76 \mathrm{~B}$ \\
SC & $37143,68 \mathrm{~B}$ & $17168,32 \mathrm{C}$ \\
CV $(\%)$ & $23288,04 \mathrm{C}$ & $29140,60 \mathrm{~B}$ \\
\hline
\end{tabular}

Médias seguidas de letras diferentes, (maiúscula) na coluna, diferem entre si ao nível de $5 \%$ de probabilidade de erro pelo teste Scott-knott $(p<0,05)$.

Em relação a espessura da casca não houve diferença estatisticamente entre as cultivares analisadas. Quanto ao ${ }^{\circ}$ Brix as cultivares que apresentaram melhores resultados foram a FB-200 e FB-300, sendo respectivamente 15,242 ${ }^{\circ}$ brix e 15,634 ${ }^{\circ}$ brix. Seguida das cultivares BRS GIGANTE AMARELO, BRS RUBI, UNEMAT 530 e SC. Sendo essa variável analisada de suma importância, pois quanto maior $0{ }^{\circ}$ Brix maior será a doçura e qualidade dos frutos. O suco possui em torno de 13 a $18 \%$ de sólidos solúveis, sendo os principais componentes os açúcares: glicose, frutose e sacarose (SEBRAE, 2015) (Tabela 3).

TABELA 3. Espessura da casca e ${ }^{\circ}$ Brix das diferentes cultivares de maracujá, cultivadas no município de Colorado do Oeste - Rondônia.

\begin{tabular}{ccc}
\hline Cultivares & Espessura da casca $(\mathbf{c m})$ & ${ }^{\circ}$ Brix \\
\hline FB-200 & $0,5460 \mathrm{~A}$ & $15,2420 \mathrm{~A}$ \\
FB-300 & $0,4480 \mathrm{~A}$ & $15,6340 \mathrm{~A}$ \\
FELTRIN & $0,5220 \mathrm{~A}$ & $12,9142 \mathrm{C}$ \\
IAC 277 & $0,6400 \mathrm{~A}$ & $12,6850 \mathrm{C}$ \\
UNEMAT 510 & $0,5840 \mathrm{~A}$ & $11,9050 \mathrm{C}$ \\
BRS GIGANTE AMARELO & $0,3840 \mathrm{~A}$ & $14,1000 \mathrm{~B}$ \\
BRS RUBI & $0,5520 \mathrm{~A}$ & $13,9350 \mathrm{~B}$ \\
UNEMAT 530 & $0,4640 \mathrm{~A}$ & $14,1200 \mathrm{~B}$ \\
SCS 437 & $0,5520 \mathrm{~A}$ & $13,2400 \mathrm{C}$ \\
SC & $0,6360 \mathrm{~A}$ & $13,6900 \mathrm{~B}$ \\
\hline CV (\%) & 28,43 & 7,36 \\
\hline
\end{tabular}

Médias seguidas de letras diferentes, (maiúscula) na coluna, diferem entre si ao nível de $5 \%$ de probabilidade de erro pelo teste Scott-knott $(p<0,05)$. 
Para o diâmetro transversal as cultivares que possuíram maior tamanho foram FELTRIN $(8,87 \mathrm{~cm})$, IAC $277(8,504 \mathrm{~cm})$, BRS GIGANTE AMARELO $(8,492 \mathrm{~cm})$, SCS $437(8,412 \mathrm{~cm})$ e SC $(8,468 \mathrm{~cm})$. Em relação ao diâmetro longitudinal a cultivar FELTRIN se destacou sobre as demais apresentando $11,08 \mathrm{~cm}$, seguida das cultivares FB-200, IAC 277, BRS GIGANTE AMARELO, SCS 437 e SC, já as demais apresentaram inferiores (Tabela 4).

TABELA 4. Diâmetro transversal $(\mathrm{cm})$ e diâmetro longitudinal $(\mathrm{cm})$ das diferentes cultivares de maracujá, cultivadas no município de Colorado do Oeste - Rondônia.

\begin{tabular}{ccc} 
Cultivares & $\begin{array}{c}\text { Diâmetro transversal } \\
\text { (cm) }\end{array}$ & $\begin{array}{c}\text { Diâmetro longitudinal } \\
\text { (cm) }\end{array}$ \\
\hline FB-200 & $8,0820 \mathrm{~B}$ & $10,3840 \mathrm{~B}$ \\
FB-300 & $7,8460 \mathrm{~B}$ & $8,8520 \mathrm{C}$ \\
FELTRIN & $8,8780 \mathrm{~A}$ & $11,0820 \mathrm{~A}$ \\
IAC 277 & $8,5040 \mathrm{~A}$ & $9,6600 \mathrm{~B}$ \\
UNEMAT 510 & $7,9480 \mathrm{~B}$ & $8,9000 \mathrm{C}$ \\
BRS GIGANTE AMARELO & $8,4920 \mathrm{~A}$ & $9,9000 \mathrm{~B}$ \\
BRS RUBI & $7,8400 \mathrm{~B}$ & $9,5040 \mathrm{C}$ \\
UNEMAT 530 & $7,8400 \mathrm{~B}$ & $8,7960 \mathrm{C}$ \\
SCS 437 & $8,4120 \mathrm{~A}$ & $10,0480 \mathrm{~B}$ \\
SC & $8,4680 \mathrm{~A}$ & $9,7840 \mathrm{~B}$ \\
\hline CV $(\%)$ & 5,12 & 5,71
\end{tabular}

Médias seguidas de letras diferentes, (maiúscula) na coluna, diferem entre si ao nível de $5 \%$ de probabilidade de erro pelo teste Scott-knott $(p<0,05)$.

\section{CONCLUSÕES}

A cultivar BRS RUBI obteve melhor resultado tanto nas águas quanto na seca, possuindo maior produtividade, alto teor de massa fresca e maior resistência a pragas e por ser de fácil adaptação ao clima da região norte.

A cultivar BRS Gigante Amarelo apresentou resultados inferiores as demais cultivares, pelo fato de apresentar uma característica negativa de uma grande queda de produção em relação ao primeiro ano de cultivo.

Quanto ao ${ }^{\circ}$ Brix as cultivares FB-200 e FB-300 apresentaram melhores ${ }^{\circ}$ Brix para as condições edafoclimáticas estudas.

\section{AGRADECIMENTOS}

Ao Instituto Federal de Educação, Ciência e Tecnologia de Rondônia Campus Colorado do Oeste, pelo apoio financeiro e incentivo a pesquisa.

Ao proprietário da Chácara Nossa Senhora Aparecida por disponibilizar a área para fins de estudo e da pesquisa.

\section{REFERÊNCIAS}

CEPLAC (2015). Comissão Executiva do Plano da Lavoura Cacaueira. Disponível em: <http://www.ceplac.gov.br/radar/maracujá.htm> Acesso em: 12 jul. 2018. 
CUNHA, M. Produtividade e características de frutos de pomares de maracujá implantados com sementes originais e reaproveitadas do híbrido BRS GIGANTE AMARELO. 2013. 64 p. Dissertação (Mestrado em Agronomia) Universidade de Brasília, Faculdade de Agronomia e Medicina Veterinária, 2013. Disponível

em: <http://repositorio.unb.br/bitstream/10482/13731/1/2013_MarlonCunha.pdf>. Acesso em: 12 jul. 2018.

FALEIRO, F. G. Efeitos do sistema de produção irrigado e sequeiro e da idade do pomar na produtividade de oito cultivares de maracujazeiro azedo no mato grosso. Bento Gonçalves-RS, 2012. Disponível em: <http://www.cpac.embrapa.br/publico/usuarios/uploads/maracujap\&d/artigoseventos/ 2_105.pdf> Acesso em: 13 jul. 2018.

FALEIRO, F.; JUNQUEIRA, T. Manual - Maracujá: o produtor pergunta, a Embrapa responde. Embrapa, Brasília-DF, 1ํed., 2016. Acesso em: 13 jul. 2018

LAGES. A. L. Biologia floral, qualidade de fruto e interferência de defensivos agrícolas em genótipos de maracujazeiro azedo no município de Tangará da Serra MT.2015. 78p. Dissertação (mestrado em Genética e melhoramento de plantas) Universidade do Estado de Mato Grosso, Unemat, Tangará da Serra, MT, 2015. Acesso em: 14 jul. 2018

MOURA, D.F.; Propriedades Benéficas do Maracujá. 2013. 26 p. Apostila (Bacharelado em Farmácia) - Farmácia, Universidade do Grande ABC, Anhanguera, 2013. Disponível em: <http://conic-semesp.org.br/anais/files/2013/trabalho1000014501.pdf>. Acesso em: 11 jul. 2018.

SANTOS, V. A. et al. Produção e qualidade de frutos de maracujazeiro-amarelo provenientes do cultivo com mudas em diferentes idades. 2016. 8 f. Artigo (Doutorado em Agronomia) - Engenharia Agronômica, Universidade Federal de Lavras, Lavras, MG, Brasil., 2016. Disponível em: <http://file:///C:/Users/S\%C3\%A1vio/Downloads/8147-29542-1-PB.pdf>. Acesso em: 13 jul. 2018.

SEBRAE, (2015). Serviço Brasileiro de Apoio as Micro e Pequenas Empresas. Disponível em: <http://www.sebrae.com.br/sites/PortalSebrae/artigos/O-cultivo-e-omercado-do-maracuja/> Acesso em: 17 jul. 2018 